\title{
PERILAKU SADARI (PERIKSA PAYUDARA SENDIRI) PADA MAHASISWA TINGKAT II PRODI D III KEBIDANAN DI STIKES KARYA HUSADA SEMARANG
}

\author{
Dyah Ayu Wulandari ${ }^{1}$, Lestari Puji Astuti ${ }^{2}$, Martina Dewi Megasari ${ }^{3}$ \\ ${ }^{1,2,3}$ Prodi D IV Kebidanan, STIKES Karya Husada Semarang
}

Email : $\underline{\text { tata.talitha@gmail.com }}$

\begin{abstract}
ABSTRAK
Latar Belakang : SADARI merupakan salah satu langkah deteksi dini untuk menemukan adanya kelainan pada payudara sehingga dengan pemeriksaan payudara sendiri maka kemungkinan adanya perubahan atau kelainan pada payudara diharapkan bisa dideteksi secara dini dan prognosisnya akan lebih baik lagi jika dilakukan pengobatan lebih awal. Tujuan : Mengeksplorasi perilaku SADARI pada mahasiswa tingkat II Prodi D III Kebidanan di STIKES Karya Husada Semarang tentang pengetahuan SADARI, keteraturan pelaksanaan SADARI, teknik melakukan SADARI, hambatan melakukan SADARI. Metode : Penelitian ini menggunakan metode kualitatif dengan pendekatan fenomenologi. Teknik pengumpulan data dengan wawancara mendalam. Jumlah partisipan 3 mahasiswa tingkat II prodi D III Kebidanan yang pernah melakukan SADARI di STIKES Karya Husada Semarang. Hasil : Pengetahuan mahasiswa tentang SADARI sudah baik. Keteraturan mahasiswa dalam melaksanakan SADARI masih belum teratur setiap bulan serta melakukan SADARI ketika mengingatnya saja. Teknik SADARI mahasiswa sudah baik, memeriksa dari payudara sampai ketiak, jika ada kelainan segera memeriksakannya. Hambatan dalam melakukan SADARI yaitu sering lupa, solusi yang dilakukan yaitu membuat pengingat atau agenda.
\end{abstract}

Kata Kunci : Perilaku; SADARI

\section{PHENOMENOLOGY STUDY OF BSE (BREAST SELF EXAMINATION) BEHAVIOUR ON STUDENTS LEVEL II OF DIPLOMA III OF MIDWIFERY AT KARYA HUSADA HEALTH SCIENCE COLLEGE SEMARANG}

\begin{abstract}
Background : BSE is one of methods early detection to find any abnormalities in the breast so that the breast self examination the possibility of changes or abnormalities in the breast are expected to be detected early and the prognosis would be better if done early treatment. Purpose : To explore the BSE behaviour on students level II of Diploma III of Midwifery at Karya Husada Health Science College Semarang, the regularity of the implementation of the BSE, techniques perform BSE, barriers perform BSE. Method : The research used qualitative method with phenomenological approach. The data collection techniques with in-depth interviews. Number of participants 3 sophomore II Program DIII Midwifery ever perform BSE in STIKES Karya Husada Semarang. Result : The results of in-depth interviews in participants obtained information about Student knowledge about BSE has been good. Regularity of students in conducting BSE is still not regularly perform breast self-exam every month and when remembering it. BSE engineering students has been good, checking of the breast to the armpit, if there is any abnormality checked immediately. Barriers to BSE that is often forgotten, solutions do is make a reminder or agenda.
\end{abstract}

Keywords : Behavior; BSE 


\section{Pendahuluan}

Kanker merupakan ancaman bagi kesehatan masyarakat diseluruh negara, terutama di negara yang sedang berkembang. Dilihat dari penyebab timbulnya kematian, kanker payudara merupakan kanker urutan pertama yang banyak menyebabkan kematian kaum wanita (Desanti,2010). Setiap tahun, 12 juta orang diseluruh dunia menderita kanker dan 7,6 juta diantaranya meninggal dunia karena kanker. Jika tidak di ambil tindakan pengendalian yang memadai, pada tahun 2030 diperkirakan 26 juta orang akan menderita kanker dan 17 juta orang akan meninggal dunia karena kanker. Kejadian in akan terjadi lebih cepat dinegara miskin dan berkembang (UICC,2009).

Di Indonesia angka penderita kanker menurut Departemen Kesehatan 2007 sebanyak 876.665 orang. Terdapat lima jenis kanker yang banyak diderita penduduk Indonesia yakni kanker payudara (350.321 kasus), kanker rahim (301.150 kasus), kanker kelenjar getah bening (122.760 kasus), kanker kulit (92.017 kasus) dan kanker rectum (57.725 kasus)(Depkes RI,2007).

Di Jawa Tengah pada tahun 2013 ditemukan sebanyak 9.145 kasus penyakit kanker,lebih sedikit dibanding tahun 2012 (11.341 kasus). Kanker payudara sebanyak 4.761 kasus (52,06\%), Kanker servik 2.295 kasus (25,10\%), Kanker hepar 1.554(16,99\%), dan Kanker paru 535 kasus (5,85\%) (Dinkes,Jateng 2013).

Prevalensi kanker payudara di Semarang pada tahun 2013 ditemukan sebanyak 832 kasus, lebih rendah dibanding tahun 2012 (998 kasus) (Dinkes,Semarang 2013). Survei dari Yayasan Kesehatan Payudara Jakarta pada tahun 2007 menunjukkan 80\% masyarakat tidak mengerti pentingnya pemeriksaan dini payudara. Hal ini dikarenakan masih rendahnya kesadaran, pengertian, dan pengetahuan masyarakat tentang kanker payudara, sementara penanganan kanker payudara secara lintas sektoral belum mendapat prioritas dari pemerintah (Desanti,2010).

Studi pendahuluan yang dilakukan oleh peneliti pada tanggal 11 Desember 2014, berupa wawancara tentang kerutinan melakukan praktik SADARI setiap bulan kepada 10 mahasiswi kebidanan tingkat II yang ada di STIKES Karya Husada Semarang didapatkan bahwa $1(10 \%)$ diantaranya menyatakan melakukan SADARI secara rutin setiap bulan tetapi tidak pada waktu yang tepat dengan alasan untuk mendeteksi adanya kelainan pada payudara dan 9 (90\%) orang lainnya tidak rutin melakukan SADARI setiap bulan dengan alasan lupa, dua diantaranya menyatakan takut bila menemukan benjolan di payudara. Dalam hal ini 
mahasiswi kebidanan tingkat II sudah mengetahui tentang pentingnya sadari tetapi lupa dantakut untuk melakukan SADARIserta tidak rutin melakukan SADARI setiap bulan.

Berdasarkan studi pendahuluan yang sudah dilakukan, peneliti tertarik untuk melakukan penelitian tentang Perilaku SADARI (Periksa Payudara Sendiri) Pada Mahasiswa Tingkat II Prodi DIII Kebidanan Di STIKES Karya Husada Semarang.

\section{Tinjauan Teoritis}

SADARI adalah pemeriksaan payudara sendiri yang bertujuan untuk mengetahui ada tidaknya kanker dalam payudara wanita. Pemeriksaan ini dilakukan oleh waniita yang berumur 20 tahun keatas(Olfah,2013:73).

Menurut Nisma (2011:25) SADARI adalah pengembangan kepedulian seorang wanita terhadap kondisi payudaranya sendiri. Tindakan ini dilengkapi dengan langkah-langkah khusus untuk mendeteksi secara awal kelainan payudara.

SADARI merupakan pemeriksaan payudara yang dilakukan sendiri yaitu dengan belajar melihat serta memeriksa perubahan payudaranya sendiri setiap bulan. Dengan melakukan pemeriksaan teratur akan dapat diketahui adanya benjolan atau masalah lain sejak dini sehingga lebih efektif untuk diobati (Depkes RI,2009:19).

Tujuan SADARI dilakukan adalah sebagai berikut:

1) SADARI hanya mendeteksi secara dini kanker payudara, bukan untuk mencegah kanker payudara. Dengan adanya deteksi dini maka kanker payudara dapat terdeteksi pada stadium awal sehingga pengobatan akan memperpanjang harapan hidup penderita kanker payudara.

2) Menurunkan angka kematian penderita karena kanker yang ditemukan pada stadium awal akan memberikan harapan hidup lebih lama( Nisman, 2011:27).

Sebaiknya pemeriksaan payudara dilakukan pada hari ke 7-10 yang dihitung setelah haid(saat payudara sudah tidak mengeras dan nyeri) atau bagi yang telah menopause pemeriksaan dilakukan dengan memilih tanggal yang sama setiap bulannya(misalnya setiap tanggal 1 atau tanggal lahirnya untuk memudahkan mengingat) (Depkes RI,2009:19).

\section{Metode Penelitian}

Desain penelitian yang akan digunakan adalah desain penelitian kualitatif menggunakan pendekatan fenomenologikal. Partisipan dalam penelitian ini adalah mahasiswa tingkat II Prodi DIII Kebidanan Di STIKES Karya Husada Semarang. 
Penelitian ini menggunakan karakter eksploratif dan tidak terdapat treatment kepada subyek penelitian. Penelitian ini dilaksanakan pada mulai dari penyusunan proposal sampai dengan turun penelitian bulan Desember 2014 sampai dengan bulan Maret 2015.

\section{Hasil Penelitian dan Pembahasan}

\section{a. Pengetahuan mahasiswa tingkat II prodi D III Kebidanan tentang SADARI}

Hasil penelitian menemukan bahwa para partisipan telah mengetahui SADARI yaitu mengenai pengertian SADARI,manfaat SADARI. Partisipan mulai mendapat informasi mengenai SADARI yaitu sejak kuliah di kesehatan sehingga sedikit banyak mereka mendapatkan ilmu kesehatan yang bukan untuk pengabdiannya saja kepada orang lain, melainkan juga kesehatan untuk merawat dirinya sendiri.

Hasil wawancara dengan triangulasi sumber mengatakan bahwa mahasiswa D III Kebidanan Tingkat II telah mengetahui tentang SADARI, manfaat dan pentingnya SADARI dilakukan karena mendapat ilmu di sekolah kesehatan.

SADARI merupakan salah satu langkah deteksi dini untuk menemukan kanker payudara stadium awal yang akan lebih efektif jika dilakukan sedini mungkin. Tindakan SADARI sangat penting karena faktanya hampir $85 \%$ benjolan payudara ditemukan oleh penderita sendiri (Desanti,2010).

Penelitian ini dapat dianalisa bahwa pengetahuan mahasiswa tingkat II Prodi D III Kebidanan mengenai SADARI sudah baik. Informasi kesehatan yang di peroleh dari perkuliahan menambah luasnya ilmu pengetahuannya sehingga di harapkan dapat diterapkan dalam kehidupan sehari-hari.

\section{b. Keteraturan Pelaksanaan SADARI Mahasiswa Tingkat II Prodi D III Kebidanan}

Hasil penelitian ini menemukan bahwa informan mulai melakukan SADARI setelah masuk kuliah di kesehatan. Pernyataan dari informan 1 dan 2 SADARI di lakukan setelah menstruasi selesai, pada informan ke 3 menjawab setiap bulan dilakukan SADARI tetapi jika ingat saja dilakukannya. Semua informan mengatakan bahwa mereka semua informan juga belum rutin menerapkan perilaku SADARI setiap bulan. Lupa dan kesibukan kuliah menjadi alasan untuk tidak rutin SADARI setiap bulan.

Hasil wawancara dengan triangulasi sumber mengatakan bahwa keteraturan pelaksanaan SADARI masih belum rutin diterapkan setiap bulan dan dengan waktu pemeriksaan yang tepat. Dengan menstruasi yang masih belum teratur juga membuat waktu untuk SADARI belum bisa dipastikan dengan tepat. 
Perilaku seseorang akan dipengaruhi oleh beberapa faktor yang menyebabkan perilakunya tidak sesuai dengan pengetahuannya. Menurut Lawrence Green dalam Notoatmodjo (2010) perilaku ditentukan oleh 3 faktor yaitu: Faktor predisposisi (Predisposing Factors) yakni terdiri dari pengetahuan, kepercayaan, sikap, keyakinan, nilai, dan sebagainya. Faktor pendukung (Enabling Factors) yang terwujud dalam lingkungan fisik, tersedia/ tidak tersedianya fasilitas/ saranan kesehatan. Faktor pendorong (Reinforcing Factors), terwujud dalam sikap dan perilaku petugas kesehatan lain

\section{c. Teknik Melakukan SADARI Mahasiswa Tingkat II Prodi D III Kebidanan}

Hasil penelitian ini menunjukkan semua partisipan sudah baik pengetahuan dan prakteknya mengenai bagaimana cara SADARI yang biasanya dilakukan yaitu dengan meraba payudara melingkar searah jarum jam dan meraba juga di daerah ketiak. Pada informan ke 2 pernah menerapkan SADARI dengan cara berdiri di depan cermin kemudian SADARI dengan berbaring sedangkan informan lainnya belum pernah mencoba untuk SADARI bercermin dan berbaring. Semua informan mengatakan bahwa jika mereka mendapati kelainan yang ditemukan di payudara, maka mereka tidak akan malu dan takut serta akan segera memeriksakan diri ketenaga kesehatan.

Hasil wawancara dengan triangulasi sumber mengatakan bahwa teknik melakukan SADARI yaitu melakukan perabaan dari payudara secara sirkuler sampai melakukan perabaan di ketiak. Pelaksanaan SADARI biasanya dilakukan di kamar mandi di asrama. Memeriksa dengan cara bercermin dan berbaring itu perlu dilakukan karena itu sesuai dengan teori SADARI. Apabila ditemukan kelainan seperti benjolan akan segera memeriksakan diri dan tidak perlu malu serta takut untuk memeriksakannya karena lebih dini diketahui maka akan memperbesar peluang untuk kesembuhannya.

Menurut Suryaningsih (2009) SADARI merupakan salah satu cara yang lebih mudah dan efisien untuk dapat mendeteksi kelainan payudara oleh diri sendiri. Perilaku SADARI yang baik dilihat dari pembuktian dengan menerapkan perilaku SADARI secara rutin.

\section{d. Hambatan Melakukan SADARI Mahasiswa Tingkat II Prodi D III Kebidanan}

Hasil penelitian ini menemukan bahwa semua informan mengatakan yang menjadi kendala tidak rutin melakukan SADARI setiap bulan adalah lupa. Cara mengatasi kendala lupa tersebut semua informan mencoba melakukan dengan membuat pengingat di tanggalan atau memo di handphone agar membantu jalannya perilaku SADARI secara rutin. Jika solusi tersebut masih belum teratasi informan 1 dan 3 mencoba untuk meminta bantuan kepada teman asrama yaitu teman yang dekat dengan partisipan. Informan ke 2 melakukan hal yang sama jika di asrama, namun jika di rumah ia meminta bantuan kepada 
orangtuanya. Alasan tidak SADARI karena takut menemukan benjolan ketika melakukan SADARI bukanlah menjadi jawaban dari Informan 1 dan 2, karena dengan SADARI akan mendeteksi sejak dini ada tidaknya kelainan pada payudara. Sebaliknya, Informan ke 3 mengatakan kadang berfikir takut untuk melakukan SADARI jika tiba-tiba muncul kelainan di payudaranya seperti benjolan.

Hasil wawancara dengan triangulasi sumber mengatakan bahwa hambatan yang sering menjadi kendala untuk melakukan SADARI adalah lupa dan malas karena banyaknya kegiatan seperti perkuliahan. Cara sederhana untuk mengatasi kendala tersebut yaitu dengan membuat pengingat seperti di kalender, alaram ataupun memo di handphone. Apabila cara tersebut masih belum bisa mengatasi kendala untuk SADARI maka meminta bantuan kepada teman terdekat dapat menjadi solusi untuk mengingatkan SADARI. Takut melakukan SADARI, karena takut menemukan kelainan di payudara merupakan langkah yang kurang tepat. SADARI akan membantu untuk medeteksi secara dini ada tidaknya kelainan di payudara, serta dengan melakukan deteksi dini otomatis penanganannya juga akan cepat.

\section{Kesimpulan}

1. Pengetahuan Mahasiswa Tingkat II Prodi D III Kebidanan Tentang SADARI, semua partisipan memiliki pengetahuan yang sudah baik mengenai SADARI.

2. Keteraturan Mahasiswa Tingkat II Prodi D III Kebidanan dalam melakukan SADARI. Semua partisipan biasanya melakukan SADARI setelah menstruasi namun ada juga yang mengungkapkan setiap bulan tetapi kalau tidak lupa.

3. Teknik Melakukan SADARI Mahasiswa Tingkat II Prodi D III Kebidanan sudah baik, semua partisipan mempraktikkan dengan benar.

4. Hambatan melakukan SADARI Mahasiswa Tingkat II Prodi D III Kebidanan adalah lupa. Semua partisipan melakukan tindakan untuk mengatasi kendala lupa yaitu dengan membuat pengingat di kalender atau dengan membuat memo alaram di HP.

\section{Saran}

Mahasiswi diharapkan untuk membuat solusi untuk pengingat SADARI seperti pengingat di Handphone atau membuat absensi SADARI setiap bulan, agar mampu untuk rutin melakukan pemeriksaan payudara sendiri. 


\section{Daftar Referensi}

Atmaningtyas, Naila. 2009. Cantik dan Sehat Payudara. Jakarta : Getar Hati

Depkes RI. 2009. Buku Saku Pencegahan Kanker Leher Rahim \& Kanker Payudara. Jakarta: Depkes RI.

Desanti, Ophi Indria. 2010. "Persepsi Wanita Berisiko Kanker Payudara Tentang Pemeriksaan Payudara Sendiri Di Kota Semarang, Jawa Tengah.” Vol.26/No.3. hlm. 152-161. Semarang: FK Universitas Islam Sultan Agung.

Farid, M.S. 2010. Mengenal Dan Mengobati Kanker Payudara.Jakarta; Vision 03.

Harningsih, Sri. 2011. Waspada Kanker Payudara. Yogyakarta : Nuha Medika.

Kusuma.2009. "Persepsi Mahasiswa Program Studi Ilmu Keperawatan Universitas Diponegoro Angkatan 2006 Jalur Reguler Yang Berisiko Terkena Kanker Payudara Terhadap Perilaku SADARI." Skripsi Program Studi Keperawatan Universitas Diponegoro.

Kartikawati, Erni. 2013. Awas!!!Bahaya Kanker Payudara \& Kanker Serviks. Bandung: Buku Baru.

Moleong, 2009.Metodologi Penelitian Kualitatif, Penerbit PT Remaja Rosdakarya Offset, Bandung

Nisma, Wenny Artanty.2011.Lima Menit Kenali PayudaraAnda. Yogyakarta: CV Andi Offset. Notoatmodjo, Soekidjo.2010.Metodologi Penelitian Kesehatan.Jakarta:Rineka Cipta.

Notoatmodjo, Soekidjo.2010. Pendidikan dan Perilaku Kesehatan. Jakarta : Rineka Cipta.

Nugraheni, Angesti. 2011. "Hubungan Tingkat Pengetahuan SADARI Dengan Perilaku SADARI Sebagai Deteksi Dini Kanker Payudara Pada Mahasiswi D IV Kebidanan Di FK UNS.” Tugas Akhir DIV Kebidanan FK Universitas Negeri Surakarta.

Nugrahini, Dewi Seftiani. 2010. “ Hubungan Tingkat Pengetahuan Dengan Perilaku SADARI Pada Mahasiswa Fakultas Ilmu Keperawatan Universitas Padjajaran" Tugas Akir Sarjana Kedokteran Program Studi Pendidikan Dokter Fakultas Kedokteran Dan Ilmu Kesehatan Universitas Padjajaran Bandung.

Olfah, Yustiana dkk. 2013. Kanker Payudara dan SADARI. Yogyakarta: Nuha Medika.

Putri, Naura. 2009. Deteksi Dini Kanker Payudara. Yogyakarta: Aura Media. 
Ranggiasanka, Aden. 2010. Waspada Kanker Pada Pria Dan Wanita. Yogyakarta: Hanggar kreator.

Rasjidi, Imam. 2009. Deteksi Dini dan Pencegahan Kanker Pada Wanita. Jakarta: CV Sagung Seto.

Riyanto, Agus. 2011. Aplikasi Metodologi Penelitian Kesehatan. Yogyakarta: Nuha Medika.

Sarwono, S. 2009. Psikologi Remaja. Jakarta : PT. Raja Grafindo Persada

Sugiyono. 2009. Metode Penelitian Kualitatif dan Kuantitatif Dan $R \& D$.

Bandung: Alfabeta.

www.dinkes-kotasemarang.go.id. . 2014. Profil Kesehatan Kota Semarang." dalam Google. Diunduh Selasa,23 Desember 2014. 